\title{
The Inner Magnetosphere Imager Mission
}

\author{
D. L. Gallagher \\ Solar Terrestrial Physics Division, NASA Marshall Space Flight Center, Huntsville, Alabama
}

\begin{abstract}
The Inner Magnetosphere Imager (IMI) mission will carry instruments to globally image energetic neutral atoms, far and extreme ultraviolet light, and $\mathrm{X}$ rays. These imagers will see the ring current, inner plasmasheet, plasmasphere, aurora, and geocorona. With these observations it will be possible, for the first time, to develop an understanding of the global shape of the inner magnetosphere and the interrelationships between its parts. Seven instruments are currently envisioned on a single spinning spacecraft with a despun platform. IMI will be launched into an elliptical, polar orbit with an apogee of approximately 7 Earth radii altitude and perigee of $4800 \mathrm{~km}$ altitude.
\end{abstract}

\section{IMI SCIENCE}

After 30 years of observing the magnetospheric environment, one of our greatest challenges remains the synthesis of individual measurements in time and space into a global picture. Many of the questions that remain pertain to the scale of physical processes and the relationships between large-scale systems. What is the global extent of the substorm injection boundary? Is the formation of such boundaries the result of very localized or spatially distributed processes? How and where is the plasmapause formed and eroded during changing geophysical conditions? What are the global electric fields? What are the phenomenological connections between the dynamic processes occurring in these major magnetospheric systems and in the auroral zone?

To date the emphasis of experimental magnetospheric studies has been the development of ground truth knowledge of fields and particles through in situ measurements. In contrast, solar and astrophysics researchers have used imaging to establish the global morphologies of distant plasma systems. With the advent of magnetospheric imaging through the IMI mission, the

\section{*For the IMI Science Definition and Preliminary Design Teams}

Solar System Plasmas in Space and Time

Geophysical Monograph 84

This paper is not subject to U.S. copyright. Published

in 1994 by the American Geophysical Union. opportunity now exists to combine our detailed in situ knowledge of magnetospheric plasmas with a global perspective of the large-scale dynamics and interactions of plasma systems. Through the imaging of photons and neutral atoms, the IMI mission will provide us global, simultaneous images of the ring current, near-Earth injection boundary, plasmasphere, auroral precipitating electrons and protons, geocorona, and outflowing ionospheric oxygen.

The IMI mission science objectives are:

1. To understand the global shape of the inner magnetosphere using simultaneously obtained images of the Earth's magnetosphere and its components: the ring current, inner plasmasheet, plasmasphere and aurora, and geocorona

2. To learn how magnetospheric current systems, field configurations, and conductivities derived from images respond on a global scale to internal and extermal influences

3. To visualize and identify the connections of various magnetospheric components to each other, especially as these connections act to change the components during substorms and solar wind variations

4. To relate global images of the magnetosphere to local observations in order to (a) leam how local processes combine to form the whole, (b) provide a global framework within which to place local observations, and (c) provide a "ground-truth" for the global observations. 
The science rationale and mission details have been forged through a close working relationship between a science working group (Table 1) and an engineering program development team (Table 2). The science working group participants represent universities, corporations, and the government. A review and evaluation of global magnetospheric imaging techniques and scientific expectations can be found in Williams et al. [1992].

\section{IMI STRAWMAN INSTRUMENTS}

The IMI measurement objective is to obtain the first simultaneous images of component regions of the inner magnetosphere; i.e., the ring current and inner plasmasheet using energetic neutral atoms (ENA), the plasmasphere using extreme ultraviolet light (EUV), the electron and proton aurorae using far ultraviolet light (FUV), and the geocorona using FUV. The strawman instrument complement is shown in Tables 3 and 4 . Seven instruments are described in these tables. Table 3 shows the spectral range and resolution, spin integrated field-of-view, angular resolution, and anticipated data rate for each instrument. Table 4 shows estimates of the requirements for accommodating each instrument on the IMI spacecraft. Volume, mass, power, pointing requirements, and operating temperatures are given.

Energetic neutral atoms are produced as a result of charge exchange between geomagnetically trapped, singly ionized ions, e.g., $\mathrm{H}^{+}, \mathrm{He}^{+}, \mathrm{O}^{+}$, and geocorona hydrogen atoms. Since little energy is exchanged during the interaction, these neutral energetic atoms carry with them information about the original ion's spatial and energy distribution and composition. The resulting luminosity of the ring current, near-Earth plasmasheet, and heliospheric sources is sufficient to be seen by the

TABLE 1. Science Definition Team

\begin{tabular}{ll}
\multicolumn{1}{c}{ Team Members } & \multicolumn{1}{c}{ Instiution } \\
\hline T.P. Armstrong (Chairman) & University of Kansas \\
D.L. Gallagher (Study Scientist) & NASA Marshall Space Flight Center \\
A.L. Broadfoot & University of Arizona \\
S. Chakrabari & Boston University \\
L.A. Frank & University of Iowa \\
K.C. Hsieh & University of Arizona \\
B.H. Mauk & Johns Hopkins University \\
D.J. McComas & Los Alamos National Laboratory \\
R.R. Meier & Naval Research Laboratory \\
S.B. Mende & Lockheed Missiles and Space Corp. \\
T.E. Moore & NASA Marsha - Space Flight Center \\
G.K. Parks & University of Washington \\
E.C. Roelof & Johns Hopkins University \\
M.F. Smith & NASA Goddard Space Flight Center \\
J.J. Sojka & Utah State University \\
D.J. Williams & Johns Hopkins University \\
\hline
\end{tabular}

TABLE 2. MSFC Preliminary Design Team

\begin{tabular}{ll}
\hline Team Members & \multicolumn{1}{c}{ Área of Responsibility } \\
\hline C.E. DeSanctis & Chief, Space Science and Applications Group \\
C.L. Johnson & Study Manager \\
M.C. Herrmann & Lead Engineer \\
R.A. Alexander & Thermal Control \\
H.R. Blevins & Communications \\
T.R. Buzbee & Conceptual Art \\
C.K. Carrington & Guidance and Control \\
H.P. Chandler & Mass Budget \\
G.A. Hajos & Configuration \\
G.B. Keams & Propulsion \\
J.H. Kim & Communications \\
L.D. Kos & Orbit Analysis \\
L.C. Maus & Power \\
F.A. Prince & Cost Analysis \\
T.L. Schmitt & Launch Vehicle \\
S.H. Spencer & Structures \\
\hline
\end{tabular}

anticipated IMI ENA imager. The detection of ENA below a few ten's keV requires a different approach than for ENA at higher energies. The use of ultra-thin foils [McComas et al., 1991, 1992] and glancing angle scattering of atoms [Herrero and Smith, 1992] are the two techniques currently being pursued for the detection of low-energy ENA. A more detailed description of these techniques and of all IMI-related imaging techniques may be found in Wilson [1993].

The first crude images of the ring current in ENA were obtained fortuitously using the medium energy particle detector on International Sun Earth Explorer 1 (ISEE 1) [Roelof et al., 1985; Roelof, 1987]. Instruments to be carried on the International Solar Terrestrial Physics (ISTP) Polar spacecraft [Voss et al., 1992] and the SAC-B satellite [Orsini et al., 1992] will be capable of imaging ENA and are expected to fly in 1994. High energy ENA imagers make use of a combination of thin foils, time-of-flight measurements, and anticoincidence discrimination to measure ENA energies and mass, while rejecting incident photons, ions, and electrons. A discussion of ENA imaging requirements can be found in Roelof et al. [1992].

Resonant scattering of solar ultraviolet light will be used by IMI to detect plasmaspheric helium, oxygen, and the geocorona. $\mathrm{He}^{+}$ions in the plasmasphere are luminous in extreme EUV light at $304 \AA$. Flux levels and, therefore, required sensitivities for an IMI $304 \AA$ imager have been established by both spacecraft and rocket experiments [Meier and Weller, 1972; Weller and Meier. 1974; Parsece et al., 1974; Chakrabarti et al., 1982]. $\mathrm{He}^{+}$ is typically found to comprise about $20 \%$ of plasmaspheric plasmas and closely follow variations in hydrogen and, therefore, total densities in the plasmasphere [Newberry et al., 1989]. A further discussion of magnetospheric helium imaging can be found in Roelof et al. [1992]. 
TABLE 3. Inner Magnetosphere Imager (IMI) Strawman Instrument Data Table Measurements

\begin{tabular}{|c|c|c|c|c|c|c|}
\hline No. & Instrument Name & $\begin{array}{c}\text { Spectral } \\
\text { Range }\end{array}$ & $\begin{array}{c}\text { Spectral } \\
\text { Resolution }\end{array}$ & $\begin{array}{l}\text { Total Field } \\
\text { of View }\end{array}$ & $\begin{array}{c}\text { Angular } \\
\text { Resolution }\end{array}$ & $\begin{array}{l}\text { Data } \\
\text { Rate }\end{array}$ \\
\hline 1 & $\begin{array}{l}\text { Hot Plasma Imager (ENA - High) } \\
\text { Hot Plasma Imager (ENA - Low) }\end{array}$ & $\begin{array}{c}20-1000 \mathrm{keV} \\
1-50 \mathrm{keV}\end{array}$ & $\begin{array}{l}\Delta \mathrm{E} /\left\langle\mathrm{E}_{\text {chan }}>=0.4\right. \\
\Delta \mathrm{E} /\left\langle\mathrm{E}_{\text {chan }}>=0.2\right.\end{array}$ & $\begin{array}{l}-9 \text { str } \\
4 \pi \text { str }\end{array}$ & $\begin{array}{l}2^{\circ} \times 2^{\circ} \\
4^{\circ} \times 4^{\circ}\end{array}$ & $\begin{array}{r}12 \\
6\end{array}$ \\
\hline 2 & Plasmasphere Imager $(\mathrm{He}+304)$ & $304 \AA$ & $50-100 \AA$ & $135^{\circ} \times 160^{\circ}$ & $0.5^{\circ}$ & 7 \\
\hline 3 & Plasmasphere Imager $(\mathrm{O}+834)$ & $834 \AA$ & $50-100 \AA$ & $135^{\circ} \times 160^{\circ}$ & $0.5^{\circ}$ & 7 \\
\hline 4 & Geocoronal Imager & $1216 \AA$ & $30 \AA$ & $4 \pi$ str. & $1^{\circ} \times 1^{\circ}$ & 2 \\
\hline 5 & Auroral Imager (FUV) & $1304 \AA, 1356 \AA, \mathrm{LBH}$ & $20 \AA$ & $30^{\circ} \times 30^{\circ}$ & $0.03^{\circ} \times 0.03^{\circ}$ & 15 \\
\hline 6 & Proton Aurora Imager & $1216 \AA \pm 40 \AA$ & $\sim 1 \AA$ & $30^{\circ} \times 30^{\circ}$ & $0.06^{\circ} \times 0.06^{\circ}$ & 8 \\
\hline 7 & Electron Precipitation Imager & $-0.3-10 \mathrm{keV}$ & $\Delta \mathrm{E} / \mathrm{E}=0.3$ & $3^{\circ} \times 3^{\circ}$ & $0.02^{\circ} \times 0.02^{\circ}$ & 2 \\
\hline
\end{tabular}

Oxygen ions will be observed by IMI in scattered EUV radiation near $834 \AA$. A blend of three $\mathrm{O}^{+}$and one $\mathrm{O}^{++}$ solar emission lines is scattered by terrestrial oxygen [Meier, 1990]. Scattering efficiencies are reported by Meier [1990] to result from a complex convolution of solar emission lines with Doppler-shifted oxygen absorption lines. The observation of magnetospheric $\mathrm{O}^{+}$ and $\mathrm{O}^{++}$in scattered solar emission will be highly dependent upon ion bulk flow and thermal velocities. In addition, the concentrations of $\mathrm{O}^{+}$and $\mathrm{O}^{++}$in the magnetosphere will be strongly dependent upon geophysical conditions and location [Roberts et al., 1987]. Discussions of magnetospheric imaging can be found in Swift et al. [1989], Chiu et al. [1990], and Garrido et al. [1991]. Oxygen imaging is further distinguished from helium $304 \AA$ imaging due to intense background ionospheric brightness near $834 \AA$. It is estimated that the ionosphere will be 2 to 4 orders of magnitude brighter than magnetospheric sources [Williams et al., 1992] in this wavelength range. The oxygen ultraviolet imaging anticipated on IMI depends upon the use of multilayer mirrors as filters. Multilayer mirror design and fabrication is an active area of research [Zukic and Torr, 1991; Chakrabarti and Edelstein, 1992].

The interpretation of ENA images depends, in part, upon our knowledge of the geocorona. Variations in geocoronal densities with solar conditions will result in changes in observed ENA intensities that are generally independent of ring current and inner plasmasheet properties. The geocorona can be seen in scattered ultraviolet light from strong solar emission in the hydrogen Lyman- $\alpha$ line at $1216 \AA$. Geocoronal Lyman- $\alpha$ observations have been made from rocket [Kupperian et al., 1959; Purcell and Tousey, 1960] and satellite [Mange and Meier, 1970; Meier and Mange, 1973] experiments. Although the geocorona is generally spherical in distribu-

TABLE 4. Inner Magnetosphere Imager (IMI) Strawman Instrument Data Accommodations

\begin{tabular}{|c|c|c|c|c|c|c|c|}
\hline No. Instrument Name & $\begin{array}{l}\text { Volume } \\
(w \times d \times h) \\
(m)\end{array}$ & $\begin{array}{l}\text { Mass } \\
(\mathrm{kg})\end{array}$ & $\begin{array}{l}\text { Avg. } \\
\text { Power } \\
\text { (W) }\end{array}$ & $\begin{array}{l}\text { Pointing } \\
\text { Stab. } \\
\text { (deg/time) }\end{array}$ & $\begin{array}{l}\text { Pointing } \\
\text { Know. } \\
\text { (deg) }\end{array}$ & $\begin{array}{l}\text { Pointing } \\
\text { Acc. } \\
\text { (deg) }\end{array}$ & $\begin{array}{l}\text { Detector } \\
\text { Temp. } \\
\left({ }^{\delta} \mathrm{C}\right)\end{array}$ \\
\hline 1 Hot Plasma Imager & $0.51 \times 0.35 \times 0.51$ & 14.0 & 4.0 & $0.50 / \mathrm{min}$ & 0.50 & 5.00 & -23 to +30 \\
\hline $\begin{array}{l}\text { Hot Plasma Imager } \\
\text { (ENA - Low) } \\
\text { Electronics Box }\end{array}$ & $\begin{array}{l}0.30 \times 0.30 \times 0.25 \\
0.30 \times 0.30 \times 0.30\end{array}$ & $\begin{array}{l}7.0 \\
8.0\end{array}$ & $\begin{array}{r}7.0 \\
12.0\end{array}$ & & & & $\begin{array}{l}-30 \text { to }+40 \\
-30 \text { to }+40\end{array}$ \\
\hline $\begin{array}{c}2 \text { Plasmasphere Imager } \\
\text { (He+304) } \\
\text { Electronics Box }\end{array}$ & $\begin{array}{l}0.48 \times 0.16 \times 0.20 \\
0.23 \times 0.18 \times 0.20\end{array}$ & $\begin{array}{r}7.2 \\
11.8\end{array}$ & $\begin{array}{r}4.5 \\
16.5\end{array}$ & $0.25 / \mathrm{min}$ & 0.25 & 0.50 & -30 to +40 \\
\hline $\begin{array}{l}3 \text { Plasmasphere Imager }(\mathrm{O}+834) \\
\text { Electronics Box }\end{array}$ & $\begin{array}{l}0.48 \times 0.16 \times 0.20 \\
0.23 \times 0.18 \times 0.20\end{array}$ & $\begin{array}{r}7.2 \\
11.8\end{array}$ & $\begin{array}{r}4.5 \\
16.5\end{array}$ & $0.25 / \mathrm{min}$ & 0.25 & 0.50 & -30 to +40 \\
\hline $\begin{array}{l}4 \text { Geocoronal Imager } \\
\text { Electronics Box }\end{array}$ & $\begin{array}{l}0.30 \times 0.60 \times 0.30 \\
0.30 \times 0.60 \times 0.30\end{array}$ & $\begin{array}{l}15.0 \\
12.0\end{array}$ & $\begin{array}{l}15.0 \\
15.0\end{array}$ & $0.50 / \mathrm{min}$ & 0.50 & 0.50 & $\begin{array}{l}\leq-100 \\
-20 \text { to }+40\end{array}$ \\
\hline $\begin{array}{l}5 \text { Auroral Imager (FUV) } \\
\text { Electronics Box }\end{array}$ & $\begin{array}{l}0.30 \times 0.70 \times 0.40 \\
0.20 \times 0.70 \times 0.40\end{array}$ & $\begin{array}{l}18.0 \\
12.0\end{array}$ & $\begin{array}{l}20.0 \\
15.0\end{array}$ & $0.06 / \mathrm{min}$ & 0.03 & 0.20 & $\begin{array}{l}\leq-100 \\
-20 \text { to+40 }\end{array}$ \\
\hline $\begin{array}{l}6 \text { Proton Aurora Imager } \\
\text { Electronics Box }\end{array}$ & $\begin{array}{l}0.60 \times 0.80 \times 0.20 \\
0.30 \times 0.80 \times 0.20\end{array}$ & $\begin{array}{l}20.0 \\
10.0\end{array}$ & $\begin{array}{l}25.0 \\
15.0\end{array}$ & $0.06 / \mathrm{min}$ & 0.03 & 0.20 & $\begin{array}{l}\leq-100 \\
-20 \text { to }+40\end{array}$ \\
\hline $\begin{array}{l}7 \text { Electron Precipitation Imager } \\
\text { Electronics Box }\end{array}$ & $\begin{array}{l}0.20 \times 0.20 \times 0.60 \\
0.25 \times 0.18 \times 0.18\end{array}$ & $\begin{array}{r}24.5 \\
3.0 \\
\end{array}$ & $\begin{array}{r}11.0 \\
9.0 \\
\end{array}$ & $0.30 / 300 \mathrm{sec}$ & 0.30 & 0.30 & Uncooled \\
\hline
\end{tabular}


tion with a power law dependence on radial distance [Wallace et al., 1970], a tailward extension [Thomas and Bohlin, 1972], dayside high-altitude depletion [Bertaux and Blamont, 1973], dawn-dusk asymmetry [Meier and Mange, 1973], and high-latitude depletion [Thomas and Vidal-Madjar, 1978] have all been observed. A source of error in observing the geocorona is from background extraterrestrial Lyman- $\alpha$ sources. Full sky maps of interplanetary and galactic Lyman- $\alpha$ intensities have been constructed by Bertaux and Blamont [1971], and by Thomas and Krassa [1971]. Long-term variation in exospheric hydrogen distributions have been found to be limited in a study by Rairden et al. [1986], using 4 years of Dynamics Explorer 1 (DE 1) observations.

Beginning with the Air Force DMSP weather service satellites [Rodgers et al., 1974], the imaging of aurora from an orbiting spacecraft has been conducted for over 20 years. During this time, several low-altitude spacecraft have observed limited portions of the aurora in visible
[Anger et al., 1973] and ultraviolet [Hirao and Itoh, 1978] light. The first complete viewing of the auroral oval was accomplished by the SAI imager on the DE 1 spacecraft [Frank et al., 1981, 1982]. This instrument viewed aurora in both visible (3175 to $6300 \AA$ ) and ultraviolet (1200 to $1800 \AA$ ) wavelengths, producing a complete image every $12 \mathrm{~min}$. Global auroral imaging has largely been used to derive a qualitative view of global magnetospheric dynamics and topology. FUV imaging on IMI will seek to obtain quantitative measures of electron precipitation energies and fluxes through the discrimination of key spectral features in auroral emission. Meier et al. [1982] determines the characteristic electron energies and energy deposition rates from rocket observations, using the relative strengths of several $\mathrm{N}_{2}$ LBH emission lines. In the same work, ionospheric atomic oxygen density is derived from $\mathrm{O}^{+}$ emissions at $1356 \AA, 1304 \AA$, and $989 \AA$. Strickland et al. [1983] demonstrated the importance of satellite FUV

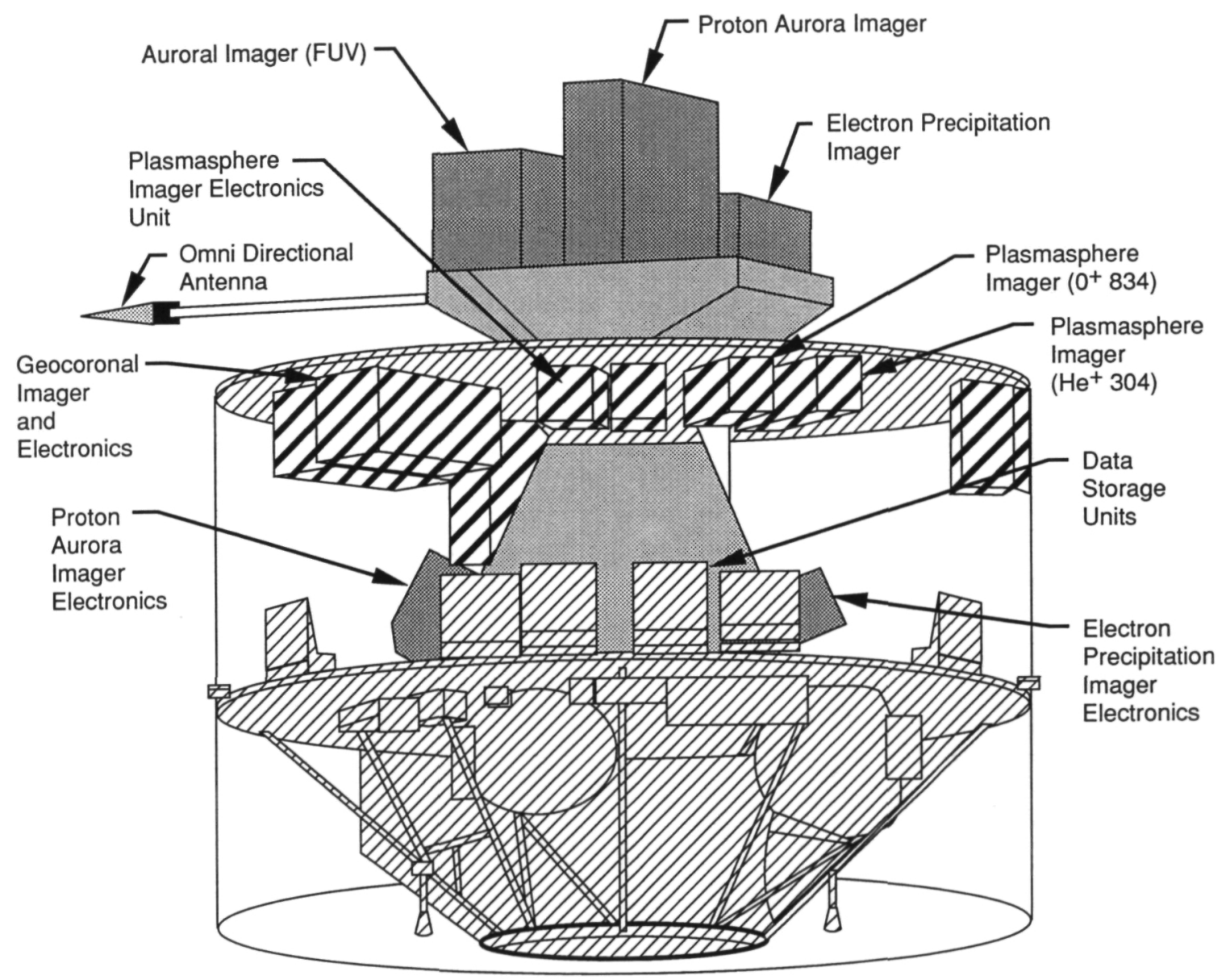

Fig. 1. Hughs HS-376 concept for IMI. 


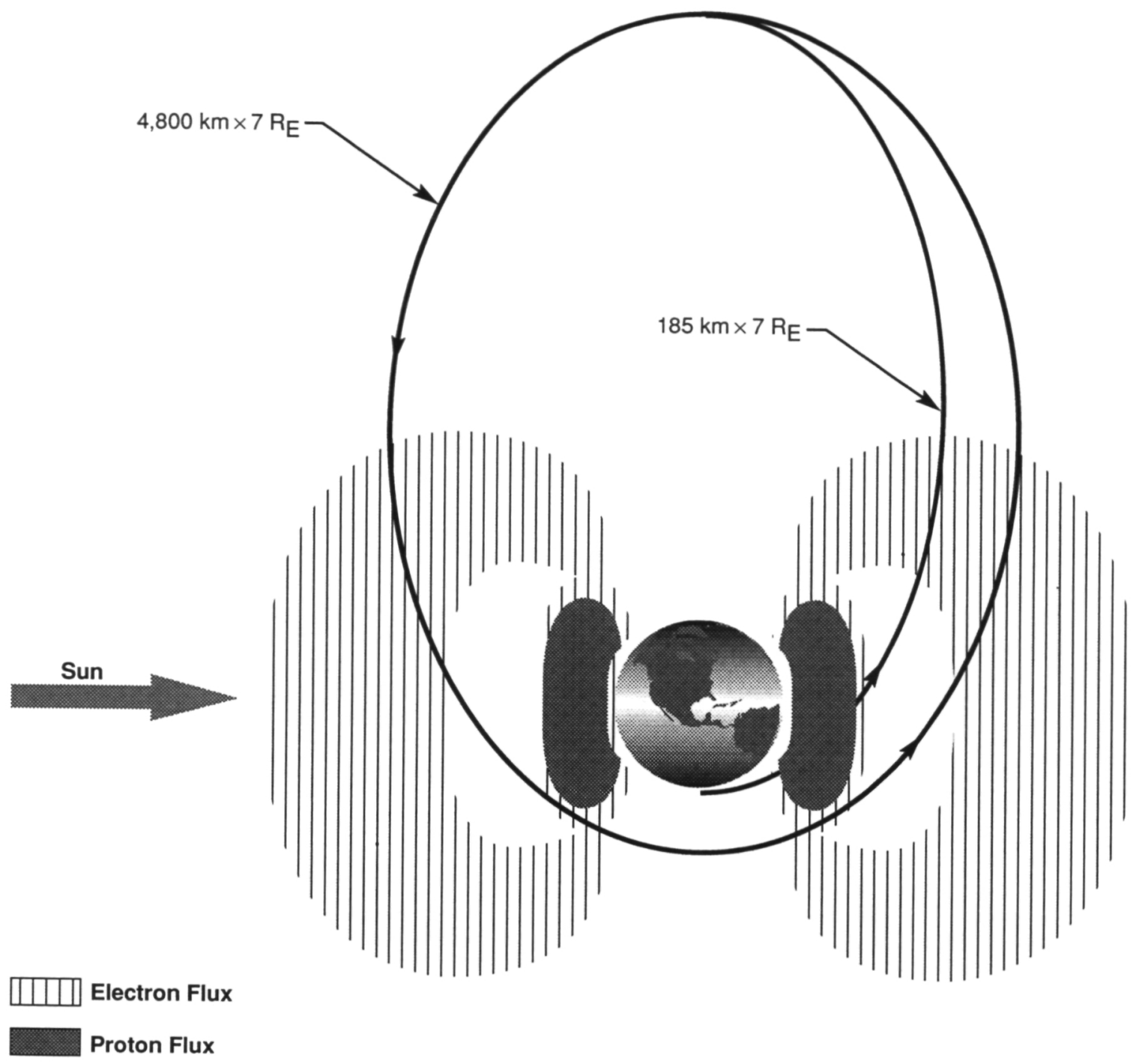

Fig. 2. lanned IMI orbit injection and perigee boost.

observations by deriving the incident auroral electron spectrum from auroral emissions of $\mathrm{N}_{2}^{+}$at $3914 \AA$, OI at $1356 \AA$, and several $\mathrm{N}_{2} \mathrm{LBH}$ bands.

IMI will also seek to quantitatively compare auroral electron and proton precipitation through the imaging of proton aurora. It has been shown by Lyons and Evans [1984] and Lyons et al. [1988] that discrete aurora, in general, occur in regions of nonadiabatic ion behavior on the nightside, rather than in regions of nonadiabatic electron behavior. In contrast, dayside nonadiabatic ion behavior may be associated with electron aurora [Lyons et al., 1987]. Ion precipitation may also play an important role in establishing ionospheric conductivity profiles during active periods [Senior et al., 1987]. Proton auroral emission results from excited hydrogen atoms produced in the ionosphere by charge exchange with precipitating energetic hydrogen ions. The anticipated IMI proton auroral imager will observe Doppler-shifted Lyman- $\alpha$ radiation in an $80 \AA$-wide band, centered at $1216 \AA$ and with a resolution of $2 \AA$. Although the geocorona Lyman- $\alpha$ emission is a relatively strong source at 1216 $\AA$, the high spectral resolution of the proton imager allows the removal of the cold geocoronal background from auroral Lyman- $\alpha$ emission. The high spectral resolution also allows a determination of precipitating proton energies. Images of proton aurora have been 


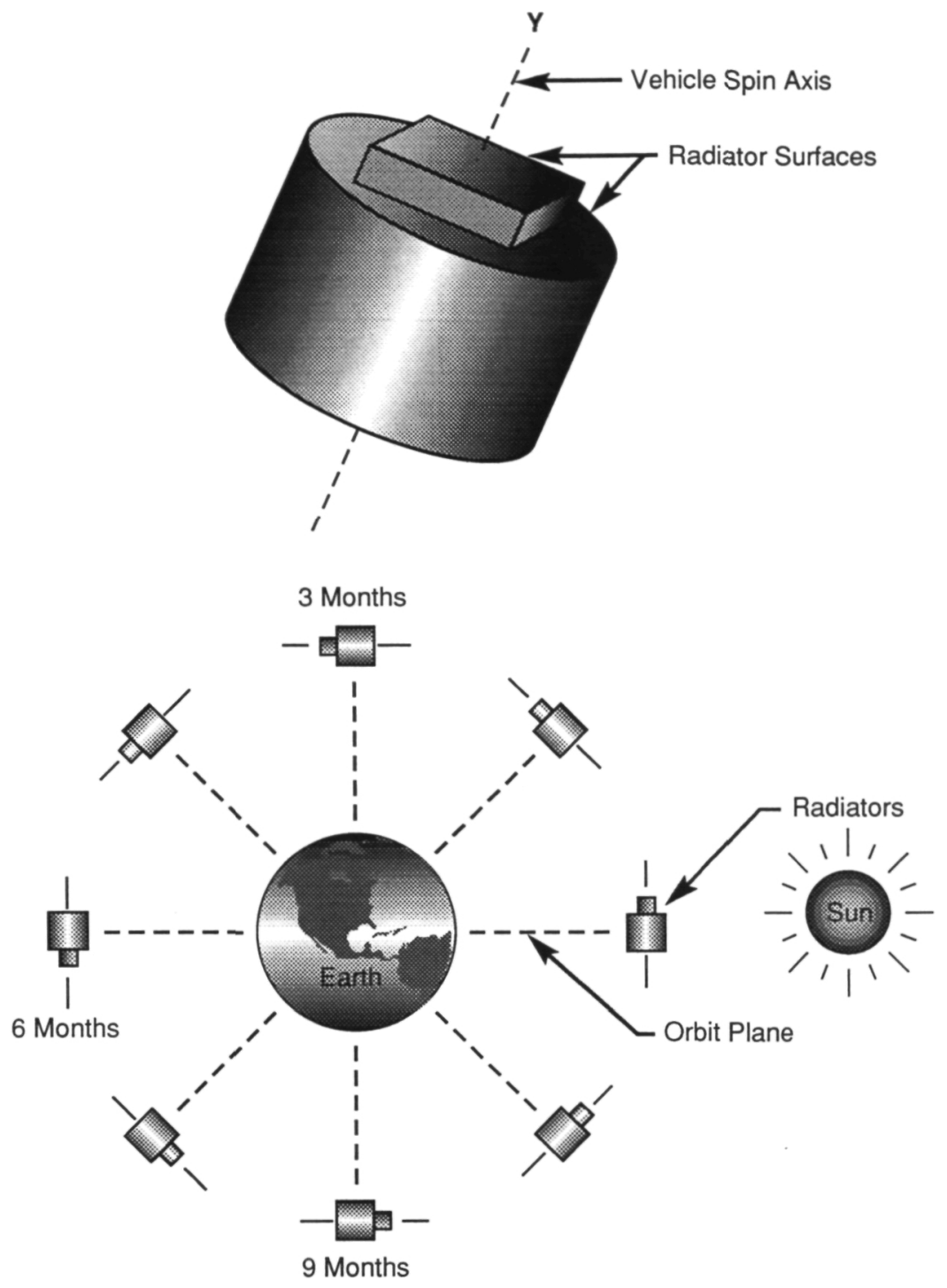

Fig. 3. Thermal control surfaces and orientations during a year.

obtained from the ground [Ono and Hirasawa, 1987] and are planned from space on the ISTP Polar spacecraft [Torr et al., 1992].

Also planned for the IMI mission is the imaging of bremsstrahlung radiation produced by auroralprecipitating electrons. The IMI electron precipitation imager will be sensitive to $X$ rays in the energy range from $0.3 \mathrm{eV}$ to $10 \mathrm{keV}$, with a spectral resolution of $\Delta \mathrm{E} / \mathrm{E}=0.3$. Estimates of precipitating electron flux and energy spectrum have been obtained from satellite-borne [Imhof et al., 1974; Mizera et al., 1984] and rocket-borne [Kremser et al., 1986] X ray experiments. Bremsstrahlung $X$ ray measurements have been established as a remote proxy for determining precipitating energetic electron characteristics through comparisons between direct electron measurement and remote $\mathrm{X}$ ray observations [Imhof et al., 1974; Mizera et al., 1978]. The first systematic use of $\mathrm{X}$ ray measurements for deriving the spectra of precipitating auroral electrons was accompished by Datlowe et al. [1988]. The ISTP Polar spacecraft will also carry an $\mathrm{X}$ ray imaging spectrometer instrument [Imhof et al., 1992; McKenzie et al., 1992], which is similar to that anticipated for IMI. This instrument will use multiple apertures at the larger distances in order to overcome low X ray luminocities. The IMI X ray imager will need to be sensitive to lower energy $X$ rays, have a higher angular resolution, and be more sensitive than the Polar instrument. 


\section{PRELIMINARY IMI SPACECRAFT DESIGN}

The preliminary design of the IMI spacecraft systems has been performed by a Marshall Space Flight Center (MSFC) Program Development team. The team members and areas of specialization are shown in Table 2. To date, two lightsat and one traditional design concepts have been studied. The more traditional design concept is based on the ISTP Polar spacecraft, built by Martin Marietta Corporation (formerly General Electric). The lightsat concepts are based on the Hughs HS-376 spacecraft, which is a spinner with a despun platform like Polar, and on a dual-spacecraft approach. Figure 1 shows a possible instrument configuration on the Hughs spacecraft. The auroral instruments, including the proton and electron auroral imagers, are mounted on a despun platform and pointed toward the Earth. The remaining instruments are mounted on the body of the spinning spacecraft. A total initial mass of $900.5 \mathrm{~kg}$ is estimated for this configuration. Of that mass the strawman instruments comprise $181 \mathrm{~kg}$, the propellent needed to raise the initial perigee is $134 \mathrm{~kg}$, and the on-orbit reaction control (RCS) system propellent is $32 \mathrm{~kg}$. The spacecraft propulsion system uses a monopropellant hydrazine in a blowdown pressurization operation.

IMI is expected to be launched from the Western Test Range. The DELTA II, Titan IIS, Taurus $120 \mathrm{XL} / \mathrm{S}$, and Conestoga launch vehicles are being considered. The initial launch will place IMI in a polar orbit with a 185 $\mathrm{km}$ altitude perigee and $7 \mathrm{R}_{\mathrm{E}}$ altitude apogee (Figure 2). At apogee on the first orbit, a kick motor will raise the IMI perigee to an altitude of $4800 \mathrm{~km}$ and an orbital

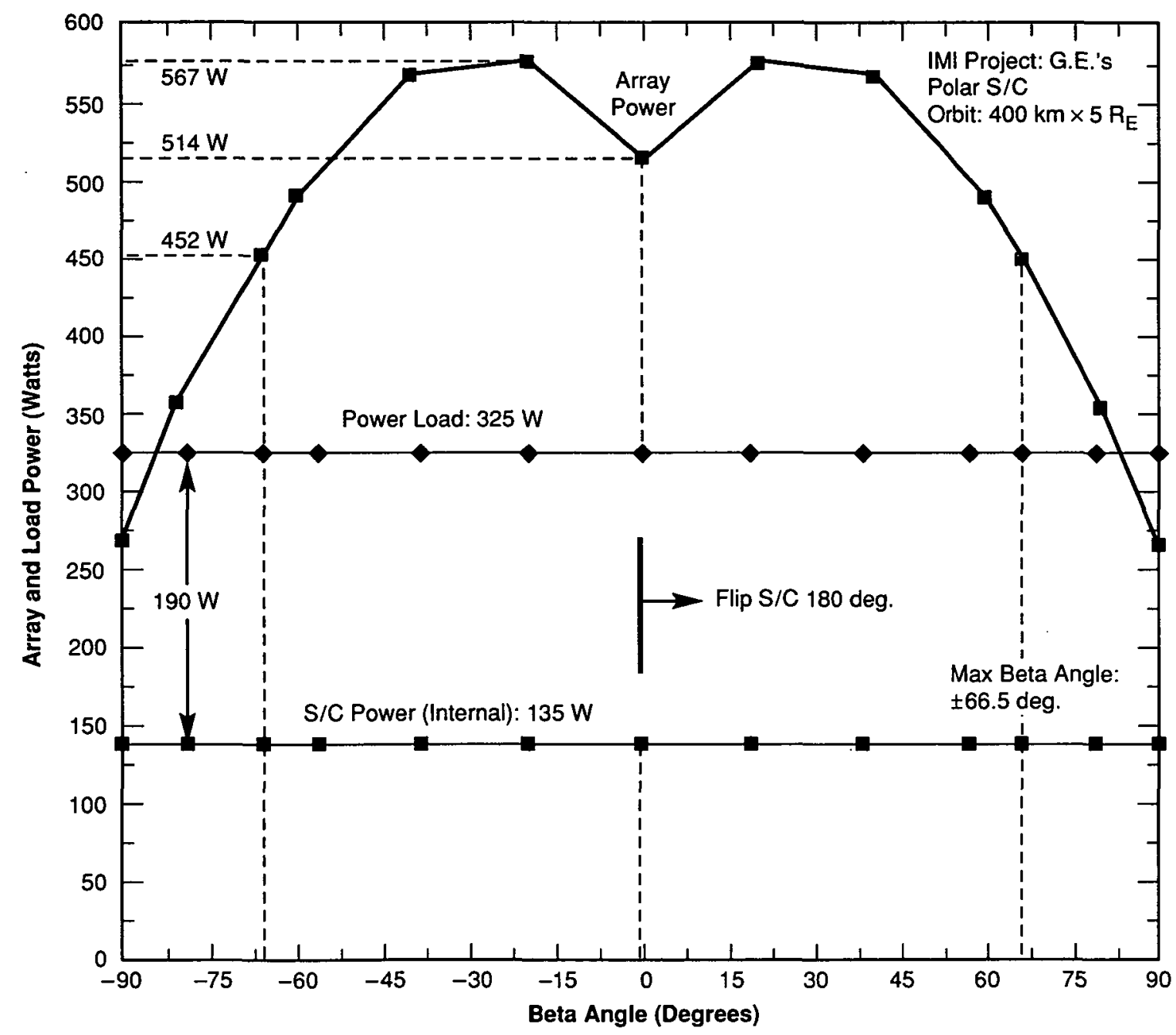

Fig. 4. Solar array and load power as a function of the angle of incidence of the Sun's light on the arrays (beta angle). 
period of about 15 hours. Over the planned 2-year lifetime of the mission, the $90^{\circ}$ inclined orbit will precess from an apogee over the northern pole to an apogee near the equator. For thermal control, a reorientation of the spacecraft is anticipated twice each year. Figure 3 shows the spacecraft orientation during the year and thermal radiating surface of the spacecraft. The reorientation is designed to keep the radiating surface pointed away from the Sun.

Electrical power is derived from approximately $14.9 \mathrm{~m}^{2}$ of body-mounted, silicon solar cells. Figure 4 shows a plot of solar array and load power as a function of beta angle for the Polar spacecraft concept. Beta angle is the angle between the normal to the spacecraft cylindrical surface and the spacecraft-Sun direction. At large angles, the solar cells receive only glancing illumination from the Sun and can provide limited power to the spacecraft. Vertical dashed lines in Figure 4 indicate the maximum estimated beta angle of $\pm 66^{\circ}$. Spacecraft reorientation is performed as the spacecraft goes through a zero beta angle. The total spacecraft systems power requirement is approximately $135 \mathrm{~W}$ and the total required instrument power is $190 \mathrm{~W}$, for a total of $325 \mathrm{~W}$. It is further estimated that cutouts for instrument viewing and thermal control will reduce the available solar cell surface area by $8 \%$. There will also be a degradation in solar cell performance over the 2-year mission lifetime of about $25 \%$. With these losses, it is projected that the minimum available solar cell power will drop from a high of $452 \mathrm{~W}$ at the maximum beta angle, as shown in Figure 4, to 355 $W$ at the end of the mission life.

NASA's deep space network (DSN) on S-band is expected to be used for the IMI mission. Instrument data rates total $59 \mathrm{kbps}$. At full instrument data rates, 1.98 gigabits of data will be generated during each orbit. Two 1.29 gigabit capacity tape recorders are planned in one of the optional mission configurations. At a playback rate of $512 \mathrm{kbps}$, a full recorder will be able to downlink its data in 42 min. A backup real-time telemetry system at 56 kbps is also being considered. This system would be limited to ground station availability and line-of-sight viewing.

Evaluation of spacecraft systems and optional configurations continues. The dual spacecraft approach would involve the use of two small spacecraft, one spinning and one three-axis stabilized. Although the relative cost advantage between single and dual spacecraft approaches has not yet been determined, it is expected that the single spacecraft option will be the better option. Spacecraft systems complexity and use of off-the-shelf elements favor the single spacecraft approach.

\section{SUMMARY}

IMI will break new ground in magnetospheric research. We will, for the first time, be able to see the global morphology of major plasma systems and the dynamic relationships between them. Old and new in situ measurements will yield new insight as a result of their placement in the global framework of magnetospheric processes provided by IMI. Ring current and near-Earth plasmasheet dynamics, including storm-time injection and depletion, will be studied by the innovative observation of oxygen and hydrogen ENA. The dynamics of plasmaspheric filling and loss due to convection will be seen through the imaging of helium scattering of EUV solar light. Storm-time ionospheric outflow of oxygen will also be seen in EUV. Polar aurora will be seen in FUV and $X$ rays. The geocorona will be seen in resonantly scattered Lyman- $\alpha$ radiation from the Sun. IMI will be launched into a $90^{\circ}$ inclined polar orbit as either one or two spacecraft. Orbital perigee will be at an altitude of $4800 \mathrm{~km}$ and an apogee altitude of $7 \mathrm{R}_{\mathrm{E}}$. IMI is expected to be a lightsat design and take the fullest advantage of technological advancements in solar cell, structure, satellite subsystems, and instrument designs.

Acknowledgments. The IMI studies are supported by the NASA Office of Space Science and Applications, Space Physics Division, Magnetospheric Physics Branch.

\section{REFERENCES}

Anger, C. D., T. Fancott, J. McNally, and H. S. Kerr, ISIS-II Scanning Auroral Photometer, Applied Opitcs, 12, 1753. 1973.

Bertaux, J. L., and J. E. Blamont, Evidence for a source of an extraterrestrial hydrogen Lyman-alpha emission: The interstellar wind, Astron. Astrophys., 11, 200, 1971.

Bertaux, J. L., and J. E. Blamont, Interpretation of OGO 5 Lyman alpha measurements in the upper geocorona, $J$. Geophys. Res., 78, 80, 1973.

Chakrabarti, S., and J. Edelstein, An $834 \AA$ reflective coating for magnetospheric imagery applications, SPIE, 1744, 208, 1992.

Chakrabarti, S., F. Paresce, S. Bowyer, Y. T. Chiu, and A. Atkin, Plasmaspheric helium ion distribution from satellite observations of He II 304 A, J. Geophys. Res. Lett., 9, 151, 1982.

Chiu, Y. T., R. M. Collin, S. Chakrabarti, and G. R. Gladstone, Magnetospheric and exospheric imaging in the extreme ultraviolet, Geophys. Res. Lett., 17, 267, 1990.

Datlowe, D. W., W. L. Imhof, and H. D. Voss, X ray spectral images of energetic electrons precipitating in the auroral zone, J. Geophys. Res., 93, 8662, 1988.

Frank, L. A., J. D. Craven, K. L. Ackerson, M. R. English, R. H. Eather, and R. L. Carovillano, Global auroral imaging instrument for the Dynamics Explorer mission, Space Sci. Instr., 5, 369, 1981. 
Frank, L. A., J. D. Craven, J. L. Burch, and J. D. Winningham, Polar views of the earth's aurora with Dynamics Explorer, Geophys. Res. Lett., 9, 1001, 1982.

Garrido, D. E., R. W. Smith, D. S. Swift, and S.-I. Akasofu, Imaging the earth's magnetosphere: Effects of plasma flow and temperature, Planet. Space Sci., 39, 1559, 1991.

Herrero, F., and M. F. Smith, Imager of low-energy neutral atoms (ILENA): Imaing neutrals from manetosphere at energies below $20 \mathrm{keV}, S P I E, 1744,32,1992$.

Hirao, K. and T. Itoh, Scientific satellite Kyokko (Exos-A), Solar Terr. Env. Res. in Japan, 2, 148, 1978.

Imhof, W. L., G. H. Nakano, R. G. Johnson, and J. B. Reagan, Satellite observations of bremsstrahlung from widespread energetic electron precipitation events, J. Geophys. Res., 79, 565, 1974.

Imhof, W. L., H. D. Voss, and D. W. Datlowe, The imaging of $\mathrm{X}$ rays for magnetospheric investigation, $S P I E, 1744,196$, 1992.

Kremser, G., A Korth, S. Ullaland, J. Stadsnes, W. Baumjohann, L. Block, K. M. Torkar, W. Riedler, B. Aparicio, P. Tanskaren, I. B. Iversen, N. Cornilleau-Wehrlin, J. Solomon, and E. Amata, Energetic electron precipitation during a magnetospheric substorm and its relationship to wave particle interaction, J. Geophys. Res., 91, 5711, 1986.

Kupperian, J. E., Jr., E. T. Byram, T. A. Chubb, and H. Friedman, Far ultraviolet radiation in the night sky, Planet. Space Sci., 1, 3, 1959.

Lyons, L. R., and D. S. Evans, An association between discrete aurora and energetic particle boundaries, J. Geophys. Res., $89,2395,1984$.

Lyons, L. R., J. F. Fennell, and A. L. Vampola, A general association between discrete auroras and ion precipitation from the tail, J. Geophys. Res., 93, 12,932, 1988.

Lyons, L. R., A. L. Vampola, and T. W. Speiser, Ion precipitation from the magnetopause current sheet, J. Geophys. Res., 92, 6147, 1987.

Mange, P., and R. R. Meier, OGO 3 observations of the Lyman alpha intensity and the hydrogen concentration beyond 5 $\mathrm{R}_{\mathrm{E}}$,J. Geophys. Res., 75, 1837, 1970.

McComas, D. J., B. L. Barraclough, R. C. Elphic, H. O. Funsten, III, and M. F. Thomsen, Magnetospheric imaging with low-energy neutral atoms, Proc. Natl. Acad. Sci. USA, $88,9598,1991$.

McComas, D. J., H. O. Funsten, III, J. T. Gosling, K. R. Moore, and $M$. F. Thomsen, Low-energy neutral-atom imaging, SPIE, 1744, 40, 1992.

McKenzie, D. L., D. J. Gorney, and W. L. Imhof, Auroral X ray imaging from high- and low-earth orbit, SPIE, 1745, 39, 1992 .

Meier, R. R., The scattering rate of solar $834 \AA$ radiation by magnetorspheric $\mathrm{O}^{+}$and $\mathrm{O}^{++}$, Geophys. Res. Lett., 17, 1613, 1990.

Meier, R. R., and P. Mange, Spatial and temporal variations of the Lyman-alpha airglow and related atomic hydrogen distributions, Planet. Space Sci., 21, 309, 1973.

Meier, R. R., and C. S. Weller, EUV resonant radiation from helium atoms and ions in the geocorona, J. Geophys. Res., 77, 1190, 1972.

Meier, R. R., R. R. Conway, P. D. Feldman, D. J. Strickland, and E. P. Gentieo, Analysis of nitrogen and oxygen far ultraviolet auroral emission, J. Geophys. Res., 87, 2444, 1982.
Mizera, P. F., D. J. Gornet, and J. L. Roeder, Auroral X ray images from DMSP-F6, Geophys. Res. Lett., 11, 255, 1984.

Mizera, P. F., J. G. Luhmann, W. A. Kolansinski, and J. B. Blake, Correlated observation of auroral arcs, electrons, and $\mathrm{X}$ rays from a DMSP satellite, J. Geophys. Res., 83, 5573, 1978.

Newberry, I. T., R. H. Comfort, P. G. Richards, and C. R. Chappell, Thermal $\mathrm{He}^{+}$in the plasmasphere: Comparison of observations with numerical calculations, J. Geophys. Res., 94, 15,265, 1989.

Ono, T., and T. Hirasawa, and C. I. Meng, Proton auroras observed at the equatorial edge of the duskside auroral oval, Geophys. Res. Lett., 14, 660, 1987.

Parsece, F., C. S. Bowyer, and S. Kumar, On the distribution of $\mathrm{He}^{+}$in the plasmasphere from observations of resonantly scattered He II 304 A, J. Geophys. Res., 79, 174, 1974.

Purcell. J. D., and R. Tousey, The profile of solar hydrogen Lyman- $\alpha, J$. Geophys. Res., 65, 370, 1960.

Rairden, R. L., L. A. Frank, and J. D. Craven, Geocoronal imaging with Dynamics Explorer, J. Geophys. Res., 91, $13,613,1986$.

Roberts, W. T., Jr., J. L. Horwitz, R. H. Comfort, C. R. Chappell, J. H. Waite, Jr., and J. L. Green, Heavy ion density enhancements in the outer plasmasphere, $J$. Geophys. Res., 92, 13,499, 1987.

Rodgers, E. H., D. F. Nelson, and R. C. Savage, Auroral photography from a satellite, Science, 183, 951, 1974.

Roelof, E. C., Energetic neutral atom images of a storm-time ring current, Geophys. Res. Lett., 14, 652, 1987.

Roelof, E. C., D. G. Mitchell, and D. J. Williams, Energetic neutral atoms (E 50 keV) from the ring current, IMP 7/8 and ISEE 1, J. Geophys. Res., 90, 10,991, 1985.

Roelof, E. C., B. H. Mauk, and R. R. Meier, Instrument requirements for imaging the magnetosphere in extreme-ultraviolet and energetic neutral atoms derived from computer-simulated images, SPIE, 1744, 19, 1992.

Senior, C., J. R. Sharber, O. De La Beujardiće, R. A Hellis, D. S. Evans, J. D. Winningham, M. Sugiura, and W. R. Hoegy, $E$ and $F$ region study of the evening sector auroral oval: $A$ Chatanika/Dynamics Explorer 2/NOAA 6 comparison, $J$. Geophys. Res., 92, 2477, 1987.

Strickland, D. J., J. R. Jasperse, and J. A. Whalen, Dependence of auroral FUV emissions on the incident electron spectrum and neutral atmosphere, J. Geophys. Res., 88, 8051, 1983.

Swift, D. W., R. W. Smith, and S.-I. Akasofu, Imaging the earth's magnetosphere, Planet. Space Sci., 37, 379, 1989.

Thomas, G.E. and R.C. Bohlin, Lyman-alpha measurements of neutral hydrogen in the outer geocorona and in interplanetary space, J. Geophys. Res., 77, 2752, 1972.

Thomas, G.E. and R.F. Krassa, OGO 5 measurements of the Lyman alpha sky background, Astron. Astrophys., 11,218 , 1971.

Thomas, G.E. and A. Vidal-Madjar, Latitude variations of exospheric hydrogen and the polar wind, Planet. Space Sci., 26, 873, 1978.

Torr, D. G., M. R. Torr, M. Zukic, J. Spann, and R. B. Johnson, The Ultraviolet Imager (UVI) for ISTP, SPIE, 1745, 61, 1992.

Wallace, L., C. A. Barth, J. B. Pearce, K. K. Kelly, D. E. Anderson, Jr., and W.G. Fastie, Mariner 5 measurements of the earth's Lyman alpha emission, J. Geophys. Res., 75, $3769,1970$. 
Weller, C. S., and R. R. Meier, First satellite observations of the $\mathrm{He}^{+} 304 \AA$ radiation and its interpretation, J. Geophys. Res., 79, 1572, 1974.

Williams, D. J., E. C. Roelof, and D. G. Mitchell, Global magnetospheric imaging, Rev. of Geophys., 30, 183, 1992.

Wilson, G. R., Inner Magnetosphere Imager (IMI) instrument heritage, NASA Contractor Report 4498, 1993.
Zukic, M., and D. G. Torr, High-reflectivity multi-layers as narrowband VUV filters, SPIE, 1485, 216, 1991.

D. L. Gallagher, ES53, NASA Marshall Space Flight Center, Huntsville, Alabama 35812. 